\title{
AS PROPRIEDADES MEDICINAIS E BIOQUÍMICAS DA PLANTA STRYPHNODENDRON ADSTRINGENS "BARBATIMÃO"
}

\author{
Érica Camila Ferreira \\ Mestranda em Neurociências/Laboratório de Fisiologia das interações Neuroquímicas/ Instituto \\ Biomédico Universidade Federal Fluminense UFF \\ ericacamilaferreira@gmail.com
}

Jorge Luiz Lima da Silva

Mestre pela Universidade Federal do Estado do Rio de Janeiro

jorgeluizlima@vm.uff.br

\author{
Raoni Ferreira de Souza \\ Enfermeiro \\ Centro Universitário Plínio Leite \\ raoniferreirasouza@gmail.com
}

\section{RESUMO}

A cultura de utilização de plantas para fins medicinais é comum nas comunidades brasileiras, devido à miscigenação de africanos e indígenas. São importantes pesquisas que comprovem a verdadeira ação dessas plantas medicinais. Esse trabalho teve por objetivo realizar revisão bibliográfica e descrever sobre o potencial medicinal da planta do cerrado brasileiro, o Stryphnodendron adstringens conhecido como "Barbatimão" destacando propriedades medicinais e bioquímicas, partes utilizadas e modo de uso popular. A pesquisa de natureza descritiva foi realizada através de revisão bibliográfica, baseada em obras primárias e secundárias publicadas entre 2001 e 2013.Stryphnodendron adstringens, conhecido como barbatimão espécie nativa do Cerrado possui dentre as propriedades medicinais apontadas, atividade antibacteriana, contra Staphylococcus aureus, antifúngica,combatendo o crescimento de Candida albicans, anticancerígeno, atividade inibitória contra alguns efeitos enzimáticos e biológicos das peçonhas de serpentes botrópicas,contra micro-organismos da cárie dental, propriedade de cicatrização, ação sobre o Trypanosoma cruzi e Leishmania amazonensis, propriedades contra úlceras, entre outras. Suas folhas, cascas possuem propriedades medicinais comprovadas, mostrado por inúmeros autores como importante agente antimicrobiano e também agente antiofídico alternativo, que pode ser utilizado com a soroterapia. Não possui atividade genotóxica, concluindo que a utilização parece ser segura e com potencial farmacológico.

Palavras-chave: Planta medicinal; antimicrobiano; antiparasitário.

\begin{abstract}
The culture of using plants for medicinal purposes is common in Brazilian communities, due to the mixing of African and indigenous. Are important studies that prove the true action of these medicinal plants. This study aimed to review the literature and describe the medicinal potential of the species from the Brazilian cerrado, the Stryphnodendron adstringens known as "Barbatimão" highlighting medical and biochemical properties, the used and popular mode of use. A descriptive research was conducted through literature review, based on primary and secondary works published between 2001 and 2013.Stryphnodendron adstringens, known as barbatimão native species of the Cerrado has among the pointed, medicinal properties antibacterial activity against Staphylococcus, Staphylococcus antifungal, combating the growth of Candida albicans, anticancer, inhibitory activity against some enzymatic and biological venoms of snakes botrópicas effects against microorganisms of dental caries, healing property, action on Trypanosoma cruzi and Leishmania amazonensis properties against ulcers, among other . Its leaves, bark have proven medicinal properties, shown by numerous authors as an important antimicrobial agent or alternate agent antivenin, which can be
\end{abstract}

Persp. online: biol. \& saúde, Campos dos Goytacazes, 11 (3), 14-32, 2013

seer.perspectivasonline.com.br 
used with antivenom. Has no genotoxic activity, concluding that the use appears to be safe and pharmacological potential.

Keywords: Medicinal plant, antimicrobial, antiparasitic.

\section{INTRODUÇÃO}

O reino vegetal é o que mais contribui para a descoberta de fármacos, dele retiramos muitas substâncias orgânicas ativas. $O$ termo planta medicinal refere-se a qualquer ser vivo do reino Plantae que pode atuar como medicamento (MELO, 2011).

$\mathrm{Na}$ arqueologia, estudos demonstram que há mais de 3.000 anos as ervas eram utilizadas para fins medicinais e que, 2.000 anos antes do aparecimento dos primeiros médicos gregos, existia o conhecimento da medicina egípcia elaborada, esse hábito de recorrer às qualidades curativas de certos vegetais foi uma das primeiras manifestações do homem para compreender e utilizar a natureza (ABIFISA, 2012).

Há grande variedade de espécies de plantas na Terra, de 250.000 a 500.000 e somente pequena parte é utilizada para o tratamento de doenças. Houve aumento da utilização de produtos naturais pela sociedade e as plantas medicinais têm sido estudadas para avaliação de compostos bioativos (ISHIDA et al., 2006).

Plantas medicinais ou suas partes não são consideradas como medicamento fitoterápico mesmo após processos de coleta, estabilização e secagem, podendo ser íntegra, rasurada, triturada ou pulverizada. Os fitoterápicos são medicamentos obtidos com exclusividade de derivados do vegetal (extrato, tintura, óleo, cera, exsudato, suco, e outros) a partir de plantas medicinais, mas devem oferecer garantia de qualidade, ter efeitos terapêuticos comprovados, composição padronizada e segurança de uso para a população (ANVISA, 2003).

Segundo Veiga Júnior (2008) não são muitas as pesquisas no Brasil, que avaliam o grau de utilização das plantas como medicamentos e sua cultura popular em relação a outros países, com pouco conhecimento dos profissionais da área de saúde sobre a cultura de utilização das plantas medicinais pela população. Entretanto isso se contrapõe ao estudo que mostra a evolução das linhas de pesquisas na ultima década relacioandas a plantas medicinais e fitoterápicos em todas regiões do Brasil (SANTOS; SIANI, 2013).

Segundo Firmo et al. (2011) pesquisadores ainda não entraram em concordância no que diz respeito de quando teve início a utilização de plantas medicinais.

Sabe-se que o conhecimento é passado de gerações em gerações por conjunto de pessoas com culturas diferentes ou semelhantes. Esse conhecimento, na maioria das vezes, é perpetuado de forma oral, assim aumentando a afetividade e, que, acaba por ser a única forma de curar ou tratar as doenças (RODRIGUES; CARVALHO, 2001, FIRMO et al., 2011).

É de extrema importância que se faça pesquisas para confirmar os verdadeiros efeitos das plantas no organismo, uma vez que, podem existir efeitos indesejáveis. Também é importante incentivar estudos etnobotânicos e etnofarmacológicos para aumentar o conjunto de informações sobre plantas medicinais, e ainda incentivar o uso sustentável dessa biodiversidade (FIRMO et al., 
2011).

Seguindo essa linha, Veiga-Júnior (2008) afirma que os profissionais da área da saúde dão pouca atenção a cultura da utilização de plantas medicinais pela população, esses profissionais até utilizam as terapias alternativas, mas terapias que não são brasileiras, como a acupuntura.

Pouco se sabe sobre a confiabilidade e segurança do uso da maioria das plantas medicinais. As pesquisas etnofarmacológicas, podem também favorecer a diminuição do tempo gasto no desenvolvimento de novos medicamentos, isto é de extrema importância para os pesquisadores e para a população (FIRMO et al., 2011).

Segundo Ethur et al. (2011), existe mercado para as plantas medicinais, fitoterápicos e necessidade de maiores informações referente à forma de cultivo, correta identificação botânica, informações ao consumidor, qualidade e eficácia dos produtos e seu uso.

A falta de boas práticas na produção e comercialização de plantas medicinais e fitoterápicos, associada à ausência de vigilância dos produtos, contribui para a diminuição da qualidade dos fitoterápicos. Para essa qualidade são necessárias adequadas práticas de identificação, cultivo, coleta, manipulação, secagem, armazenamento e transporte, como indicado na Resolução RDC $\mathrm{n}^{\circ}$ 306, de 07 de dezembro de 2004 da Agência Nacional de Vigilância Sanitária (ANVISA), o que não ocorre com produtos comercializados popularmente (BARBOSA et al., 2010).

Existem limitações terapêuticas, no tratamento de infecções causadas por fungos, bactérias e parasitas, como a resistência aos medicamentos, á toxicidade da droga, interações medicamentosas e a biodisponibilidade insuficiente das drogas que estão disponíveis atualmente no mercado, isso têm chamado a atenção para o desenvolvimento de medicamentos que seriam capazes de tratar infecções que adquirem resistência. A obtenção de novos agentes contra fungos, bactérias e parasitas (MELO et al., 2009, HERZOG-SOARES et al., 2002).

O Brasil tem a maior floresta equatorial e tropical úmida do mundo, flora considerada de estimada biodiversidade, com cinco grandes áreas, compostas por diversidade de plantas nativas e dentro dessas áreas, está o segundo maior bioma, o cerrado (MELO, 2011).

O bioma cerrado é um complexo vegetacional que possui grande diversidade biológica, que ocupa extensa área territorial nas regiões centrais do Brasil, e com maior concentração populacional (RODRIGUES; CARVALHO, 2001). O cerrado está localizado no Planalto Central com extensão de $2.036 .448 \mathrm{Km}^{2}$, ocupando $23,92 \%$ do território nacional, sendo o bioma que inclui formações savânicas, florestais e campestres e ainda apresenta aéras de transição com todos os biomas brasileiros com exceção do Pampa que se localiza no Sul (EMBRAPA, 2008).

O cerrado esta entre as mais ricas savanas do mundo e possui heterogeinidade muito grande, composta por espécies endêmicas, plantas com potencial medicinal, alimentício, madeireiro, melífero. Mas sua riqueza contradiz com o ritmo acelerado de desmatamento, correndo o risco de perder a biodiversidade e consequente perda de novas moléculas inovadoras para o tratamento de doenças (SANO; ALMEIDA; RIBEIRO, 2008). 
No Brasil, a utilização de plantas medicinais vem da miscigenação cultural envolvendo africanos, europeus e indígenas, por isso, essa cultura é tão diversa e para muitas dessas comunidades brasileiras é o único recurso terapêutico (MELO et al., 2007, MELO, 2011).

Uma das plantas do cerrado utilizada é o Stryphnodendron barbadetiman, (Figura 1), sinônimo, Sryphnodendron adstringens conhecido como barbatimão, barba-de-timão, borãozinhoroxo, casca-da-virgindade, uabatimô (ALMEIDA et al., 1998, SILVÉRIO, 2008 apud MELO, 2011, GLASENAPP, 2011).

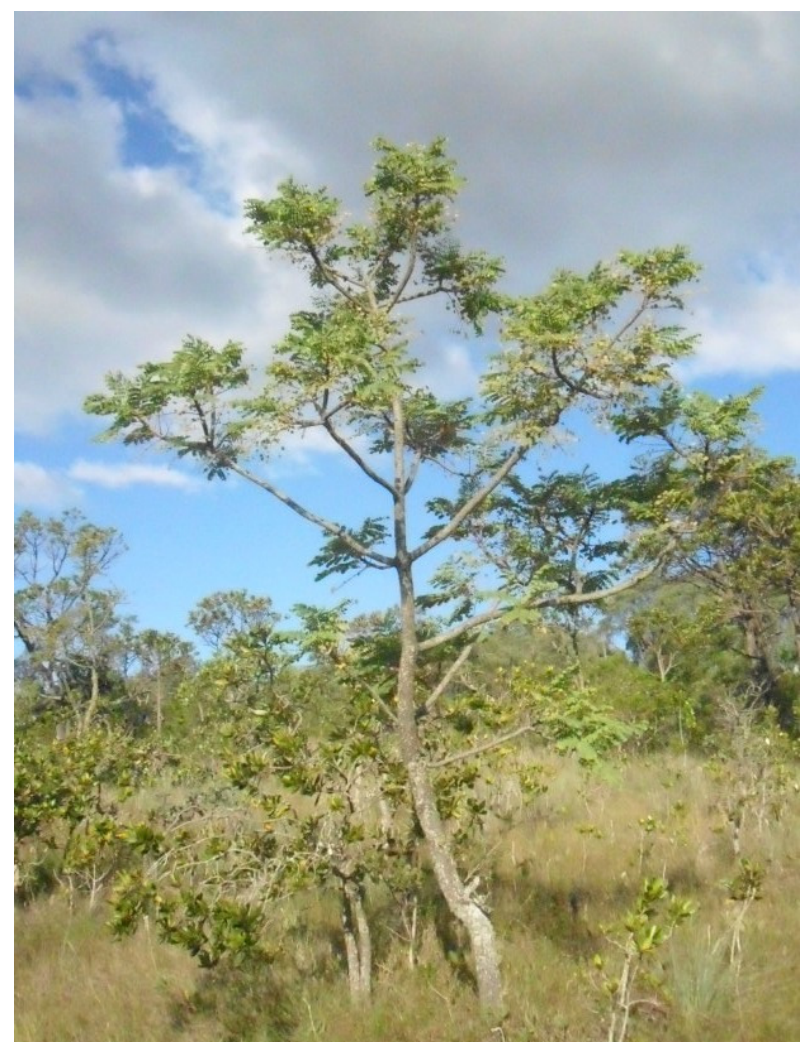

Figura 1 - Arbusto de Sryphnodendron adstringens, popularmente conhecido como barbatimão localizado no município de São Tomé das Letras - MG(área de formação florestal do cerrado).

É conhecida pelo seu uso externo e interno no corpo pelo conhecimento empírico, são utilizadas cascas e folhas, as cascas são mais usadas, supostamente por serem mais adstringentes (Figura 2 e 3). O chá da casca e o extrato alcoólico são utilizados em doenças como, infecções vaginais, hemorragia, úlceras de pele e estômago, diarreia, disenteria (ALMEIDA et al., 1998, SILVÉRIO, 2008 apud MELO, 2011, GLASENAPP, 2011). 


\section{PERSPECTIVASonline}

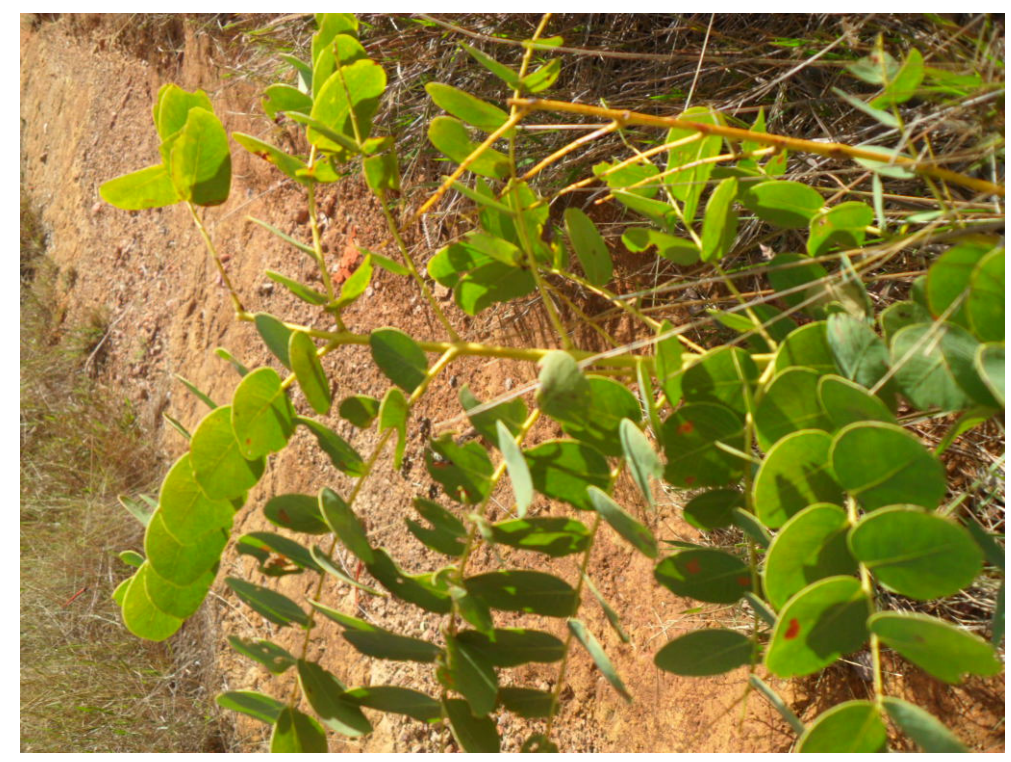

Figura 2-Folhas deSryphnodendron adstringens"barbatimão".

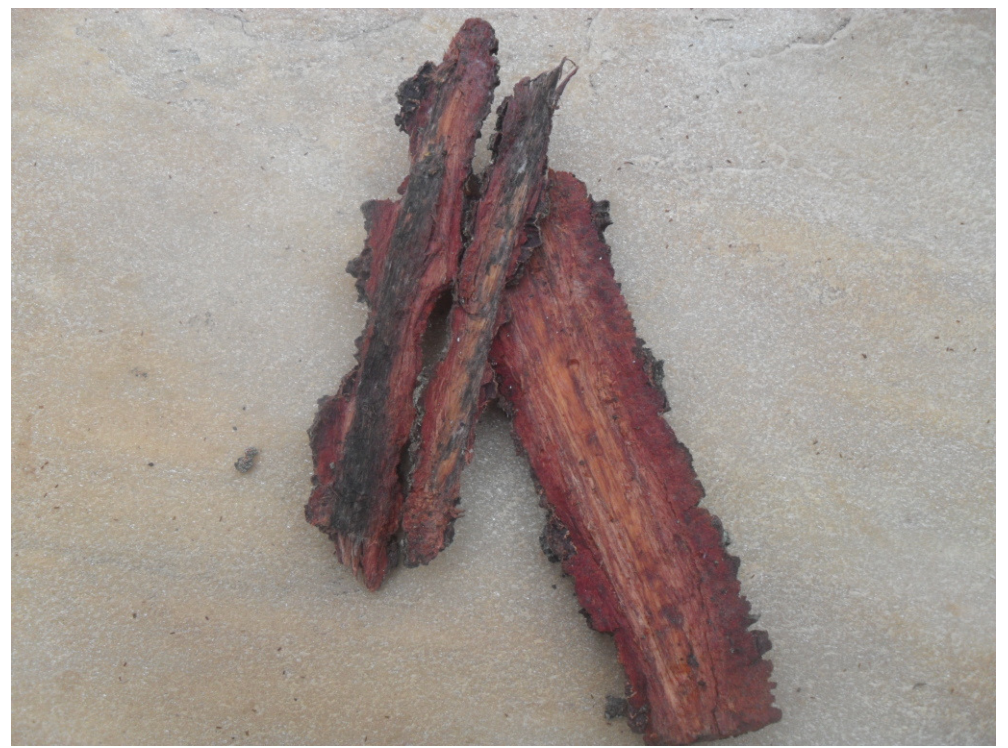

Figura 3 - Casca do Stryphnodendron adstringens "barbatimão".

O Stryphnodendron adstringens é rico em taninos e ainda outros constituintes químicos, como alcaloides, flavonoides, terpenos, estilbenos, esteroides, inibidores de proteases (como a tripsina) que podem ser responsáveis pela sua atividade anti-inflamatória e supostamente antimicrobiana. Os taninos presentes nessa planta são os principais componentes vegetais que possuem a propriedade de precipitar as proteínas da pele e das mucosas, transformando-as em substâncias insolúveis (ABIFISA, 2010, MONTEIRO; DE ALBUQUERQUE; ARAÚJO, 2005, VASCONCELOS et al., 2004).

Persp. online: biol. \& saúde, Campos dos Goytacazes, 11 (3), 14-32, 2013 
Devido à habilidade de ligar-se às proteínas e outras macromoléculas, por sua adstringência, os taninos também apresentam atividades tóxicas. Outro mecanismo de toxicidade é o fato desses, complexarem-se com facilidade a íons metálicos. Sistemas biológicos, incluindo micro-organismos, necessitam de íons metálicos como cofatores enzimáticos, um exemplo dessa toxicidade são ratos quando tratados com bebidas ricas em compostos fenólicos tiveram redução da absorção de ferro (SCALBERT, 1991 apud MONTEIRO; DE ALBUQUERQUE; ARAÚJO, 2005).

Os taninos são considerados nutricionalmente indesejáveis porque precipitam proteínas, inibem enzimas digestivas, prejudicando mais ainda pessoas que possuem prisão de ventre e afetam a utilização de vitaminas e minerais podendo, ainda, em alta concentração, desenvolver câncer de bochecha e esôfago (CHUNG; WEI; JOHNSON, 1998, CHUNG, K. et al., 1998 apud MONTEIRO; DE ALBUQUERQUE; ARAÚJO, 2005, ALMEIDA et al., 1998, SILVÉRIO, 2008 apud MELO, 2011 ).

O objetivo deste trabalho foi fazer um levantamento bibliográfico, mostrando o potencial medicinal da planta do cerrado brasileiro, o Stryphnodendron adstringens conhecido como barbatimão, destacando suas propriedades medicinais e bioquímicas, o que se usa desta planta e modo de uso popular.

Podem se descobrir substâncias capazes de curar uma grande diversidade de doenças relacionadas com agentes inflamatórios, como bactérias, fungos e parasitas com plantas vindas do cerrado brasileiro que possui variedade enorme de plantas endêmicas, que são utilizadas pela medicina empírica, essas plantas devem ser estudadas para melhor atender a população, como o Stryphnodendron adstringens, barbatimão (SOARES; VINHOLISA e SILVA 2008, LUIZE et al., 2005, HERZOG-SOARES et al., 2002, PINHO et al., 2012).

\section{MATERIAL E MÉTODO}

A pesquisa foi de natureza descritiva realizada através de revisão bibliográfica, baseada em obras primárias e secundárias que abordam o tema em questão: As propriedades medicinais e bioquímicas da planta Stryphnodendron adstringens "barbatimão", publicadas no período de 2001 a 2013. A coleta do material para a pesquisa foi realizada no período de 2012 a 2013.

O levantamento foi realizado em bancos de informações, pesquisa livre na Pubmed, Scielo, Lilacs, onde foram incluídas nos resultados de busca obras completas de língua espanhola, inglesa ou portuguesa e suas respectivas traduções. Os descritores utilizados foram: Planta medicinal; antimicrobiano; antiparasitário, pesquisados de forma associada e isolados. Ressaltando que a coleta de material no Scielo foi realizada através da busca por assunto, pois neste banco de informações não se utiliza busca por descritores.

Foram selecionados para esta pesquisa somente artigos que, na leitura dos resumos, se enquadrassem como: As propriedades medicinais e bioquímicas da planta Stryphnodendron adstringens "barbatimão", utilizando como fonte de informações, periódicos da área biológica, biomédica, farmacêutica e médica, que estavam disponíveis nos locais escolhidos para a coleta das informações.

Os descritores foram associados para chegar ao número ideal de artigos. Excluindo os artigos que o objeto de estudo não contribuía para o alcance do objetivo, obtendo total de 25 artigos.

Persp. online: biol. \& saúde, Campos dos Goytacazes, 11 (3), 14-32, 2013

seer.perspectivasonline.com.br 


\section{RESULTADO E DISCUSSÃO}

Realizada a seleção das obras foram descartados os estudos repetidos e os que não tinham relação com as propriedades medicinais e bioquímicas da planta Stryphnodendron adstringens "barbatimão". No final, foram obtidos 25 artigos para embasamento teórico e desenvolvimento do estudo. Além do conteúdo encontrado na pesquisa na BVS, obras complementares (completas) foram utilizadas, pesquisa de livros na biblioteca física de uma universidade privada, biblioteca municipal, onde foram selecionadas as obras mais recentes e que mostrassem relação com o objeto de estudo, os quais deram subsídio conceitual; 4 monografias (incluindo teses e dissertações); 25 artigos, 3 sites e 4 livros, totalizando 36 documentos de língua espanhola, inglesa e portuguesa.

Para atender o objetivo geral nesta seção são descritos os resultados das obras analisadas dispostas no Quadro 1, a seguir. São especificados a Ação Medicinal e o micro-organismo inibido ou célula na qual o fitoterápico age.

\begin{tabular}{|c|c|c|c|}
\hline Ação Medicinal & Alvo da Ação & $\begin{array}{l}\text { Espécie do micro-organismo } \\
\text { inibido ou célula na qual o } \\
\text { fitoterápico age }\end{array}$ & Referência \\
\hline $\begin{array}{l}\text { Influência de taninos a } \\
\text { partir de Stryphnodedndron } \\
\text { adstringens sobre fatores de } \\
\text { virulência e crescimento. }\end{array}$ & Atividade antifúngica. & Candida albicans. & $\begin{array}{lll}\text { Ishida } & \text { et } & \text { al. } \\
(2006) & & \end{array}$ \\
\hline $\begin{array}{l}\text { Atividade antimicrobiana } \\
\text { (AA) de extratos } \\
\text { hidroalcoólicos frente a } \\
\text { micro-organismos isolados } \\
\text { de focos de infecções } \\
\text { clínicas. }\end{array}$ & Atividade antibacteriana. & $\begin{array}{lrr}\begin{array}{l}\text { Streptococcus } \\
\text { mirabilis, Syogenes, }\end{array} & \begin{array}{l}\text { Proteus } \\
\text { Shigella }\end{array} \\
\text { Staphylococcus } & & \text { aureus, } \\
\text { Staphylococcus spp coagulase } \\
\text { negativa (IFI), e Staphylococcus } \\
\text { aureus e Staphylococcus epidermidis } \\
\text { (ATCC). }\end{array}$ & $\begin{array}{l}\text { Gonçalves } \\
\text { (2007) }\end{array}$ \\
\hline $\begin{array}{l}\text { Barbatimão } r \text { como } \\
\text { adjuvante no controle da } \\
\text { cárie dental. }\end{array}$ & Atividade antibacteriana. & $\begin{array}{l}\text { O extrato hidroalcoólico bruto de } \\
\text { barbatimão foi ativo frente aos } \\
\text { micro-organismos Streptococcus } \\
\text { mitis, e Lactobacillus casei. }\end{array}$ & $\begin{array}{l}\text { Soares; } \\
\text { Vinholisa } \\
\text { Silva (2008) }\end{array}$ \\
\hline $\begin{array}{lr}\begin{array}{l}\text { Neutralização } \\
\text { principais dos }\end{array} & \text { efeitos } \\
\text { enzimáticos e biológicos de } \\
\text { peçonhas botrópicas } \\
\text { brasileiras pelo } \\
\text { extrato aquoso de } \\
\text { stryphnodendron } \\
\text { adstringens. }\end{array}$ & $\begin{array}{l}\text { Ação inibitória contra } \\
\text { alguns efeitos enzimáticos } \\
\text { e biológicos das peçonhas } \\
\text { de serpentes botrópicas. }\end{array}$ & $\begin{array}{l}\text { O extrato aquoso (Eva) apresenta } \\
\text { propriedades neutralizantes da } \\
\text { peçonha de serpentesbotrópicas. }\end{array}$ & $\begin{array}{l}\begin{array}{l}\text { Lucena } \\
(2008)\end{array} \\
\text { et al. }\end{array}$ \\
\hline $\begin{array}{l}\text { Efeito de extratos vegetais } \\
\text { sobre atividades biológicas } \\
\text { do veneno da serpente } \\
\text { Lachesis muta. }\end{array}$ & $\begin{array}{l}\text { Efeito inibitório sobre } \\
\text { atividades biológicas do } \\
\text { veneno da serpente } \\
\text { Lachesis muta. }\end{array}$ & $\begin{array}{l}\text { O extrato de Stryphnodendron } \\
\text { barbatiman } \\
\text { eficientemente todas as atividades } \\
\text { avaliadas. }\end{array}$ & De Paula (2009) \\
\hline $\begin{array}{llr}\begin{array}{l}\text { Efeitos } \\
\text { crescimento, }\end{array} & \text { sobre } & \text { tamanho da } \\
\text { cápsula } & \text { e } & \text { pigmentação } \\
\end{array}$ & Agente antifúngico. & $\begin{array}{l}\text { Os taninos extraídos de } S . \\
\text { adstringens exibe uma importante } \\
\text { atividade biológica contra } \quad C .\end{array}$ & $\begin{array}{l}\text { Ishida et al. } \\
(2009)\end{array}$ \\
\hline
\end{tabular}

Persp. online: biol. \& saúde, Campos dos Goytacazes, 11 (3), 14-32, 2013

seer.perspectivasonline.com.br 


\begin{tabular}{|c|c|c|c|}
\hline $\begin{array}{l}\text { sobre atividade de taninos a } \\
\text { partir de Stryphnodendron } \\
\text { adstringens no } \\
\text { Cryptococcusneoformans. }\end{array}$ & & neoformans. & \\
\hline $\begin{array}{l}\text { Potencial antifúngico } \\
\text { principalmente para tratar } \\
\text { infecções e feridas contra } \\
\text { os fungos patogênicos. }\end{array}$ & Agente antifúngico. & $\begin{array}{l}\text { Candida albicans e Trychophyton } \\
\text { rubrum. }\end{array}$ & $\begin{array}{l}\text { Melo E Silva, } \\
\text { De Paula E } \\
\text { Espindola, } \\
\text { (2009) }\end{array}$ \\
\hline $\begin{array}{l}\text { Atividadeantigenotóxica de } \\
\text { extratos de folhas de } S \text {. } \\
\text { adstringens sobre a } \\
\text { genotoxicidadeinduzida. }\end{array}$ & Agenteanticancerígeno & $\begin{array}{l}\text { O aquoso a fração de água e } \\
\text { etanólicoextratos de folhas foram } \\
\text { obtidos e apresentaram alto teor de } \\
\text { compostos fenólicos, flavonoides } \\
\text { eproantocianidinas. Inibida a } \\
\text { genotoxicidade induzida pela } \\
\text { ciclofosfamida. Inibiu a formação de } \\
\text { lesão do DNA ediminuiu } \\
\text { significativamente a formação de } \\
\text { micronúcleos. }\end{array}$ & $\begin{array}{l}\text { Filho et al. } \\
(2011)\end{array}$ \\
\hline 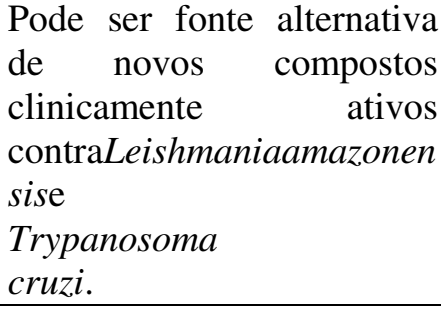 & $\begin{array}{l}\text { Efeito significantecontra } \\
\text { parasitas. }\end{array}$ & $\begin{array}{l}\text { Testados contra formas } \\
\text { amastigotaaxênica e promastigota de } \\
\text { Leishmania } \quad \text { (L.)amazonensis, e } \\
\text { formas epimastigota de Trypanosoma } \\
\text { cruzi in vitro. }\end{array}$ & $\begin{array}{l}\text { Luize et al. } \\
(2005)\end{array}$ \\
\hline $\begin{array}{l}\text { Atividade inibitória sobre o } \\
\text { Staphylococcus aureus. }\end{array}$ & Atividade antibacteriana. & $\begin{array}{l}\text { Staphylococcus aureus, } \\
\text { Streptococcus pneumoniae, Bacillus } \\
\text { antracis e Shigella dysenteriae. }\end{array}$ & $\begin{array}{l}\text { Santos e Alves } \\
(2012)\end{array}$ \\
\hline $\begin{array}{l}\text { Combate a infecção } \\
\text { urinária. }\end{array}$ & Atividade antibacteriana. & $\begin{array}{lr}\text { Proteus mirabilis, } & \text { Staphylococcus } \\
\text { epidermidis, } & \text { Enterobacter sp., } \\
\text { Staphylococcus } & \text { saprophyticus, } \\
\text { Staphylococcus } & \text { aureus, } \\
\text { Staphylococcus sp., Escherichia coli, } & \text { E } \\
\text { BGN-NF, } & \text { Citrobactersp., } \\
\text { Enterobacter } & \text { aggomerans, } \\
\begin{array}{l}\text { Pseudomonas aeroginosa, Klebsiella } \\
\text { oxytoca. }\end{array} & \\
\end{array}$ & $\begin{array}{l}\text { Thomazi, } \\
\text { Bertolin e Pinto } \\
\text { (2010) }\end{array}$ \\
\hline $\begin{array}{l}\text { Os extrato obtidos das } \\
\text { folhas contêm metabólitos } \\
\text { com potencial } \\
\text { antimicrobiano. }\end{array}$ & Atividade antibacteriana. & Staphylococcus aureus. & $\begin{array}{l}\text { Pinho et al. } \\
\text { (2012) }\end{array}$ \\
\hline $\begin{array}{ll}\text { Forma alternativa } & \text { no } \\
\text { controle de parasitoses } & \end{array}$ & $\begin{array}{l}\text { Interferência sobrea curva } \\
\text { de parasitemia do } \\
\text { Trypanosoma cruzi. }\end{array}$ & Trypanosoma cruzi. & $\begin{array}{l}\text { Herzog-Soares } \\
\text { et al. }(2002)\end{array}$ \\
\hline
\end{tabular}

Quadro 1: Distribuição das obras eleitas para análise, publicadas no período de 2001 a 2013período de levantamento de 2012 a 2013. 


\section{CATEGORIAS OBSERVADAS NAS REFERÊRNCIAS UTILIZADAS}

Após, realizada leitura na íntegra de todo o material selecionado, foram então, categorizados conforme assunto e opinião de cada autor no que diz respeito a: as propriedades medicinais e bioquímicas da planta Stryphnodendron adstringens "barbatimão". Surgiram, então, 2 categorias: uso de Stryphnodendron adstringens como ação antimicrobiana e Stryphnodendron adstringens para outras afecções.

\section{1. $\quad 1^{\text {a }}$ Categoria: Uso de Stryphnodendron adstringenscomo ação antimicrobiana}

\section{Atividade antibacteriana}

Em pesquisa realizada por Gonçalves (2007), para avaliar atividade antimicrobiana de várias espécies de arvóres medicinais nativas brasileiras contra dez micro-organismos, o Stryphnodendron adstringens mostrou importante atividade antimicrobiana contra os micro-organismos com ação contra Streptococcus pyogenes, Proteus mirabilis, Shigella flexneri, Staphylococcus aureus, Staphylococcus spp coagulase negativa, e Staphylococcus epidermidis.

Pinho et al. (2012) avaliaram o perfil fitoquímico de extratos hidroalcoólicos padrão (EAPs), obtidos a partir das folhas de plantas incluindo barbatimão (Stryphnodendron adstringens)e a atividade antimicrobiana de diferentes concentrações desses EAPs contra Staphylococcusaureus e Escherichia coli. Os EAPs não mostraram atividade sobre E.coli, todavia as folhas de barbatimão evidenciaram potencial para inibir o crescimento de $S$. aureus. O uso da folha e casca dessa espécie vegetal pode constituir-se numa alternativa sustentável, viável e acessível para tratamento antimicrobiano.

Ainda nesse mesmo contexto Soares, Vinholisa e Silva (2008) avaliaram a atividade antibacteriana do extrato bruto do barbatimão frente à micro-organismos da cárie dental, utilizando cepas padrão de Enterococcus faecalis, Streptococcus salivarius, Streptococcus sanguinis, Streptococcus mitis, Streptococcus mutans, Streptococcus sobrinus e Lactobacillus casei.

A determinação da Concentração Inibitória Mínima (CIM) do extrato hidroalcoólico bruto de barbatimão, utilizou o método da diluição em caldo. Como resultado final a CIM do extrato do barbatimão variou de 350 a $>400 \mu \mathrm{g} / \mathrm{Ml}$, sendo considerado ativo contra $S$. mitis e L. casei, sugerindo então o uso de extrato de barbatimão como auxiliar no controle da cárie dental (SOARES; VINHOLISA; SILVA, 2008).

Soares, Vinholisa e Silva (2008) avaliaram a atividade antibacteriana do extrato hidroalcoólico bruto do barbatimão contra micro-organismos da cárie dental, sobre as cepas padrão Enterococcus faecalis, Streptococcus salivarius, Streptococcus sanguinis, Streptococcus mutans, Streptococcus sobrinus e a ação antibacteriana observada sugere o uso do extrato de Stryphnodendron adstringens.

Em estudo dos extratos, Thomazi, Bertolin e Pinto (2010) testaram a casca de $S$. adstringens e a folha de $H$. speciosa que apresentaram o maior potencial antibacteriano. A casca de $S$. adstringens apresentou o maior número de espécies sensíveis (12 espécies), ação contra: Proteus mirabilis, Staphylococcus epidermidis, Enterobacter sp., Staphylococcus saprophyticus, Staphylococcus aureus, Staphylococcus sp., Escherichia coli, BGN-NF, Citrobacter sp., Enterobacter aggomerans, Pseudomonas aeroginosa, Klebsiella oxytoca. 
Para oito espécies bacterianas testadas (P. mirabilis, Enterobacter sp., Staphylococcus sp., Citrobacter sp., S. saprophyticus, E. agglomerans, $K$. oxytoca e BGN-NF) não há registro literatura sobre atividade antibacteriana da casca de $S$. adstringens. No entanto, para as espécies $S$. aureus, E. coli, S. epidermidis, P. aeruginosa, Bacillus cereus, Enterococcus faecalis, Neisseria gonorrhoeae, Shigella flexneri, outras espécies de Klebsiella, assim como Streptococcus mitis, Lactobacillus casei, e espécies de Candida, foi comprovada ação contra estes micro-organismos (THOMAZI; BERTOLIN; PINTO, 2010).

\section{Agente antifúngico}

Em estudo Ishida et al., (2006) realizaram a investigação da atividade antifúngica do Stryphnodendron adstringens, utilizando seu extrato bruto obtido a partir da casca seca contra C.albicans. Para a pesquisa foi utilizado antifúngicos de referência o Fluconazol e Nistatina, utilizando o método de microdiluição em caldo.

Foi obtido o extrato com acetona a 70\% em água em $20 \mathrm{~min}$, o solvente foi eliminado, liofinizado descrito como F1(fração 1), desta fração (F1) foi suspenso em água e repartiu-se com acetato de etila para obter uma de água descrito como F2 outra de etila descrito como F3. A F2 foi cromatrogafada em proporções volumétricas com etanol água (50\%, etanol a 70\%, 90\% etanol e acetona 70\%), obtendo-se: subfrações F2.1 (0,35 g), F2.2 (0,54 g), F2.3 (0,03 g) e F2.4 (1,08 g; $54 \%$ ). Houve atividade, o barbatimão interfere com o crescimento, fatores de virulência e ainda possui baixa toxicidade as células, sua ação foi parecida com a Nistatina usada contra candidíase e pouco menos satisfatória que o Fluconazol usado contra dermatomicoses e candidíase (ISHIDA et al., 2006).

Essa ação antifúngica do barbatimão se dá pela subfração F2, tem esse nome por ser a fração rica em polímeros proantocianidinas incluindo vários flavan-3-ois, como prodelphinidins e prorobinetinidins, esses são atribuídos a taninos condensados (protoantocianidinas). Através desses resultados é preciso mais investigação dos mecanismos de ação, para desenvolver novo agente antifúngico, uma vez que mostrou atividades antifúngicas satisfatórias em relação ao padrão drogas testadas (ISHIDA et al., 2006, ISHIDA et al., 2009, MELO et al, 2009).

Melo et al. (2009) avaliaram o potencial antifúngico de plantas do cerrado, em destaque as plantas que são utilizadas para curar infecções e feridas, contra Candida albicans e Trychophyton rubrum. Os melhores extratos foram testados em concentrações menores e suas concentrações inibitórias mínimas (MIC) foram determinadas pelo método de microdiluição. Os extratos apresentaram médias de concentrações inibitórias mínimas (MIC) entre 170,39 e 23,23 mg/ml.

O Stryphnodendron adstringens mostrou atividade promissora contra o Trychophyton rubrum, onde teve considerável zona de inbição perto e até maior que o Itraconazol e também mostrou atividade contra Candida albicans (MELO et al, 2009).

Outra pesquisa feita por Ishida et al. (2009) avaliou a atividade dos taninos a partir do Stryphnodendron adstringens, sobre o fungo Criptococcus neoformans em relação ao seu crescimento, pigmentação e tamanho da cápsula. Constatou que os taninos vindos da planta Stryphnodendron adstringens possui atividade biológica contra esse o fungo, interfere com os fatores de virulência de $C$. neoformans, ou seja, age contra homeostase celular, fermentação crescimento, formação e tamanho da cápsula de polissacarídeo e pigmentação, sendo considerado candidato para novos agentes antifúngicos. 
A ação antifúngica da subfração F2 (fração do polímero rico em proantocianidina) que é rica em polímeros proantocianidinas incluindo vários flavan-3-ois, como prodelphinidins e prorobinetinidins do Stryphnodendron adstringens em $C$. albicans podem ser atribuídos a taninos condensados. A atividade antifúngica é considerada moderada. Estas propriedades do "barbatimão" sobre o crescimento de C.albicans, fatores de virulência e sua suposta baixa citotoxicidade justifica mais estudos para investigar os mecanismos de ação e o possível desenvolvimento de um novo agente antifúngico (ISHIDA et al., 2006).

Ishida et al. (2009) avaliaram a atividade dos taninos a partir da planta Stryphnodendron adstringens sobre o Criptococcus neoformans, no que diz respeito ao crescimento, tamanho da cápsula e pigmentação. interfere com: homeostase celular, fermentação crescimento, formação e tamanho da cápsula de polissacarídeo e pigmentação dos fungos, todos os fatores de virulência importantes de $C$. neoformans, e pode ser considerado como um candidato forte para o desenvolvimento de novos agentes antifúngicos.

A avaliação da segurança da fração de polímero rico em proantocianidinas obtida da casca do caule de Stryphnodendron adstringens (barbatimão) para utilização como um agente farmacológico indicaram que fração do polímero rico em proantocianidina (F2) obtido a partir de casca do caule de $S$. adstringens não tem atividade genotóxica. Assim, o uso de F2 parece ser seguro a respeito da genotoxicidade, e esta fração tem potencial como um agente farmacológico, principalmente de tratamento antifúngico (COSTA et al., 2010).

A descoberta de novos fitoterápicos representa desafio para a comunidade científica, pois muitas drogas existentes para o tratamento, por exemplo, de infecções fúngicas, bacterianas e parasitárias possuem estreito espectro de ação, efeitos adversos e toxicidade (ISHIDA et al., 2006).

\section{Efeito significante contra parasitas}

Em estudo Luize et al. (2005) descrevem a triagem de extratos obtidos de 19 espécies de plantas usadas na medicina tradicional brasileira para o tratamento de várias doenças. Os extratos foram testados contra formas amastigota axênica e promastigota de Leishmania (L.) amazonensis, e formas epimastigota de Trypanosoma cruzi in vitro na concentração de $100 \mu \mathrm{g} / \mathrm{ml}$. Baccharis trimera, Cymbopogon citratus, Matricaria chamomilla, Mikania glomerata, Ocimum gratissimum, Piper regnellii, Prunus domestica, Psidium guajava, Sambucus canadensis,Stryphnodendron adstringens, Tanacetum parthenium, e Tanacetum vulgare apresentaram efeito significante contra um ou ambos parasitas, com a porcentagem de inibição de crescimento entre 49,5 e 99\%. Os extratos não mostraram efeito citotóxico em hemácias de carneiro. Essas plantas medicinais podem ser fontes alternativas de novos compostos clinicamente ativos contra L. amazonensis e T. cruz.

Stryphnodendron adstringens e o Caryocarbrasiliensis são espécies nativas do Cerrado e vem sendo testadascomo forma alternativa no controle de parasitoses evetores. Em pesquisa Herzog-Soares et al. (2002) avaliaram a ação dos extratos brutoetanólicos das cascas destas espécies na concentração de 400ppm, sobre a parasitemia do Trypanosoma cruzi. Os resultados demonstraram que durante as quantificações, os extratos de S. adstringens e de C.brasiliensis apresentaram uma significativa interferência sobre a curva de parasitemia do T. cruzi, reduzindo o número de parasitosno sangue. 


\section{2. $\quad 2^{\mathrm{a}}$ Categoria: Ação do Stryphnodendron adstringenspara outras afecções}

Melo (2011) destaca em seu estudo as propriedades medicinais, partes utilizadas e modo de uso de várias plantas do cerrado, inclusive o Stryphnodendron adstringens, conhecido como barbatimão, dele constatou que pode ser feito chá, cozimento da erva, banhos, emplastros, garrafadas, pós e extratos alcóolicos.

Em estudo feito por Rodrigues e Carvalho (2001) em uma microregião no sul do Estado de Minas Gerais, levantaram-se as espécies mais usadas na medicina popular e o como estas são manipuladas, constatou que essas plantas nativas são para curar inúmeros tipos de doenças e as formas de chás, em decocto (cozimento de partes mais duras) ou infusas são mais utilizadas. O Stryphnodendron adstringens (barbatimão) é uma das plantas utilizadas. Com partes da casca do caule, é feito cozimento (decocção), é adstringente, cicatrizante, serve para nablenorragia, diarreia, hemorragia, úlceras e uretrites; ainda utiliza-se contra calvície, fazendo o cozimento da casca do caule, raiz e folhas aplicando diretamente na área (RODRIGUES; CARVALHO, 2001, MELO, 2011).

O barbatimão é uma importante planta medicinal, uma vez que é indicado para várias doenças, como, corrimento vaginal, hemorragias uterinas e intestinais, feridas abertas, úlceras do estômago e duodeno diarreia, leucorreia, afecções escorbúticas, hérnia, para esses males são feitos chás das cascas. Ainda utilizam as cascas da planta com alcóol, sendo essa mais adstringente, com efeito cicatrizante, antidiarreíco, antiblenorrágico, indicado para úlceras e uretrites, contra tumores, gastrite. Folhas e cascas são tônicas podendo ser usadas contra tosses, queimaduras, feridas malignas, oftlamias crônicas, escorbuto e lavagens vaginais. Esse potencial medicinal se dá por suas substâncias, taninos que torna a planta adstringente (MELO, 2011).

Melo (2011), em revisão sobre o potencial medicinal das plantas do Cerrado, destaca as propriedades medicinais, partes utilizadas e modo de uso do Barbatimão (Stryphnodendron adstringens): são utilizadas folhas e cascas, sendo as cascas mais ricas em tanino por isso mais adstringentes.

\section{Efeito inibitório da ação do veneno da serpente Lachesis muta}

O Stryphnodendron adstringens além de ter atividades antimicrobianas comprovadas (ISHIDA et al., 2006, SOARES; VINHOLISA; SILVA, 2008, MELO et al., 2009, GONÇALVES, 2007, ISHIDA et al., 2009). Pode ser de acordo com De Lucena, Mendes e Brandeburgo (2008) um importante neutralizante de peçonhas de serpentes botrópicas, pois ao investigar os efeitos inibitórios do extrato aquoso a partir da casca do caule seca, contra alguns efeitos enzimáticos e biológicos causados por peçonhas das botrópicas, efeitos esses como, atividade hemolítica, onde foram utilizados os controles, salina, veneno das serpentes $(20 \mu \mathrm{g})$ e o extrato aquoso da planta $(100 \mu \mathrm{g})$. Na ausência do extrato aquoso, a peçonha de Bothrops moojeni fez a formação de um halo e a peçonha de Bothrops pauloensis também fez a formação do halo, ou seja, houve atividade do veneno.

Depois da aplicação das peçonhas incubadas com o extrato aquoso de Stryphnodendron adstringens, aconteceu a inibição de $100 \%$ da atividade da peçonha de Bothrops moojeni na razão de 1:5 (m/m, peçonha/extrato) e inibição de $84 \%$ da atividade da peçonha de Bothrops pauloensis na razão de 1:10 (m/m, peçonha/extrato) (DE LUCENA; MENDES; BRANDEBURGO, 2008).

Em relação à atividade fibrinogenolítica, ou seja, proteínas proteolíticas presentes nas peçonhas alteram atividade do fibrinogênio, causando hemorragia. $\mathrm{O}$ extrato aquoso fez com que 
ocorresse a inibição das proteases de Bothrops moojeni e Bothrops pauloensis (ibid).

No que diz respeito à letalidade, $99 \mathrm{mg} / \mathrm{Kg}$ de extrato aquoso são capazes de inibir em 100 $\%$ a mortalidade induzida por Bothrops pauloensis e $80 \%$ da mortalidade induzida por Bothrops moojeni. No quadro 3 a seguir, mostra os resultados da inibição da letalidade induzida pelas peçonhas brutas por Stryphnodendron adstringens (ibid).

$\mathrm{Na}$ atividade miotóxica quando a peçonha bruta de Bothrops moojeni foi incubada com o extrato aquoso na razão de $1: 1(\mathrm{~m} / \mathrm{m}$, peçonha/extrato) atividade miotóxica foi inibida; na peçonha de Bothrops pauloensis foi inibida na proporção de 1:5 (m/m, peçonha/extrato). O extrato apresenta propriedades que neutralizam a peçonha de serpentes. Pode ser usado para o tratamento com a soroterapia, uma vez que possui potencial inibidor de toxinas (ibid).

De Paula (2009) também pesquisou e avaliou plantas brasileiras que poderiam ser antiofídicas, contra as atividades biológicas: hemolítica, hemorrágica, coagulante, e proteolítica do veneno de L. muta. Os extratos vegetais foram preincubados com o veneno de L. muta na proporção veneno/planta 1:10 e ensaiados para as diferentes atividades biológicas.

Em relação à atividade de hemólise indireta as plantas E. Alba, M.fallax, M.selowiana e T. stenoscarpa tiveram resultado de $100 \%$ de inibição; a $M$. velluntina com resultado de $86,67 \%$; S.barbatiman (Stryphnodendron adstringens) com inibição de 84,16\%; M.albicans com 75,68\%; J.ellyptica 44,16\%; M. glomerata com 21,70\%; C.sylvestris 10,62\%.

No que diz respeito à atividade hemorrágica as plantas S.barbatiman, M.fallax, M.albicans, T. stenoscarpa inibiram em $100 \%$ essa atividade; seguido de M. velluntina com $80,77 \%$; E. Alba com 75,00\%; M.selowiana 71,16\%; C.sylvestris $61,54 \%$ e as plantas M. glomerata e J.ellyptica não inibiram a atividade hemorrágica.

Para a atividade de coagulação, E. Alba, M. velluntina e S.barbatiman obtiveram 100\%; T. stenoscarpa teve 61,66\%; M.fallax com 33,33\%; J.ellyptica 20\%; C.sylvestris 18,33\%; M. glomerata $15 \%$ e as plantas M.albicans e M.selowiana tiveram $0 \%$.

$\mathrm{Na}$ atividade proteolítica, E. Alba, J.ellyptica, M.fallax, M.albicans, M.selowiana, T. stenoscarpa, C.sylvestris tiveram $100 \%$ de inibição da atividade proteolítica, seguido de S.barbatiman com $98,74 \%$; M. glomerata $64,56 \%$; M. velluntina $60,76 \%$. Lembrando que a planta S.sapindus não obteve resultado nenhum em todas as atividades testadas, hemólise, hemorragia, coagulação e proteolítica.

$\mathrm{Na}$ comparação dos resultados dos testes com as diferentes plantas o extrato de Stryphnodendron adstringens neutralizou todas as atividades avaliadas, mesmo que em algumas atividades osresultados tenham sido inferiores a outras plantas, em média esse extrato alcançou mais de $80 \%$ das atividades tóxicas e pode ser utilizado como fonte alternativa para acidentes ofídicos pela L.muta, pois possue moléculas com propriedades antiofídicas. Abaixo o quadro 4 com os resultados dos testes para atividades biológicas.

Comparando os quadros, De Lucena, Mendes e Brandeburgo (2008) e De Paula (2009), pesquisaram a ação de plantas contra alguns efeitos enzimáticos e biológicos causados por peçonhas de serpentes, O primeiro estudo pesquisou o veneno de botrópicas (Bothrops moojeni e Bothrops pauloensis) e o segundo avaliou a peçonha de Lachesis muta, avaliaram os efeitos da ação das plantas contra a atividade hemolítica, onde De Lucena, Mendes e Brandeburgo (2008) comprovam

Persp. online: biol. \& saúde, Campos dos Goytacazes, 11 (3), 14-32, 2013

seer.perspectivasonline.com.br 
na ausência do extrato aquoso de Stryphnodendron adstringens a peçonha de Bothrops moojeni e Bothrops pauloensis fizeram a formação de um halo, com o extrato de Stryphnodendron adstringens houve a inibição da atividade da peçonha de $100 \%$ de Bothrops moojeni e $84 \%$ de Bothrops pauloensis. A formação do halo refere-se à atividade hemolítica positiva, quando há formação, significa que houve inibição da quebra das hemácias.

Com a pesquisa de De Paula (2009) a atividade hemolítica do veneno da Lachesis muta foi inibida pelo Stryphnodendron adstringens em $84,16 \%$, ou seja, ambas as pesquisas comprovaram o efeito inibitório da planta Stryphnodendron adstringens contra a hemólise.

$\mathrm{Na}$ atividade hemorrágica segundo De Lucena, Mendes e Brandeburgo (2008) o extrato aquoso de Stryphnodendron adstringens fez com que ocorresse a inibição da hemorragia e no estudo feito por De Paula (2009) também teve resultado em $100 \%$ na hemorragia e coagulação. Na ação proteolítica segundo De Paula (2009) houve resultado de 98,74\% de inibição com resultado satisfatório também para a pesquisa De Lucena, Mendes e Brandeburgo (2008).

Somente De Lucena, Mendes e Brandeburgo (2008) analisou a ação do extrato contra a letalidade, com resultado de 99mg / Kg de extrato aquoso são capazes de inibir em $100 \%$ a mortalidade induzida por Bothrops pauloensis e $80 \%$ da mortalidade induzida por Bothrops moojeni e também a atividade miotóxica onde o extrato também inibiu essa ação.

Pesquisa feita por De Paula (2009) o extrato de S. barbatiman foi capaz de inibir de forma significativa, com percentual acima de $80 \%$ para todas as atividades biológicas testadas, hemolítica, coagulante, hemorrágica e proteolítica do veneno de L. muta, e também na pesquisa feita por De Lucena, Mendes e Brandeburgo (2008) todas essas atividades foram satisfatórias.

De Paula (2009) avaliou doze plantas encontradas na flora brasileira como antiofídicas frente às atividades: hemolítica, coagulante, hemorrágica e proteolítica do veneno de L. muta. Os extratos vegetais, incluindo da planta Stryphnodendron adstringens de Mikania glomerata, Jatrophaa ellyptica e Casearia sylvestris mostraram inibição cerca de $30 \%$ sobre grande parte das atividades testadas. Os extratos de Eclipta Alba, Miconia fallax, Miconia selowiana, Miconia albicans e Tibouchina stenoscarpa mostraram inibição superior a $30 \%$ frente a três das quatro atividades testadas., diferente do extrato aquoso de Sapindus sapindus que não fora capaz de neutralizá-las. Os extratos vegetais que apresentaram um perfil ativo poderiam ser utilizados como fonte alternativa no envenenamento causado pela serpente $L$. muta, pois tais extratos são fontes ricas de moléculas com propriedades antiofídicas.

Lopes et al. (2009) desenvolveram método de separação e quantificação por cromatografia líquida de alta eficiência, onde foi feito análise quantitativa de três espécies de Stryphnodendron, afirmando que o teor de galocatequina é similiar entre as espécies e que o Strynodendron adstringens possui $60 \%$ a mais de ácido gálico (Tanino) do que as outras espécies. Essa metodologia é viável para plantas ricas em taninos como o S. adstringens, S. polyphyllum e S. obovatum. 
A seguir o quadro 2 expõe as propriedades da planta Stryphnodendorn adstringens, de acordo com os autores.

\begin{tabular}{|l|l|l|l|}
\hline $\begin{array}{l}\text { Ação } \\
\text { antibacteriana }\end{array}$ & $\begin{array}{l}\text { Ação } \\
\text { antifúngica }\end{array}$ & $\begin{array}{l}\text { Ação } \\
\text { antiofídica }\end{array}$ & Substância e partes usadas \\
\hline $23,53 \%$ & $29,41 \%$ & $11,76 \%$ & $\begin{array}{l}100 \% \text { se referiu aos taninos } \\
\text { como principais } \\
\text { componentesem relação às } \\
\text { atividades da planta } \\
\text { Stryphnodendron a } \\
\text { adstringens.Sendo que, as } \\
\text { partes usadas 66,66\% refere- } \\
\text { se a casca do caule e 33, 33\% } \\
\text { refere-se a casaca e folhas. }\end{array}$ \\
\hline
\end{tabular}

Quadro 2: porcentagem referente as propriedades da planta Stryphnodendron adstringens de acordo com os autores, referidos a $2^{\circ}$ categoria ação do Stryphnodendron adstringens como antimicrobianao e para outros males.O restante das porcentagens estão referidos a $1^{\circ}$ categoria de uso de plantas medicinais.

Poderá ser utilizado como uma alternativa para o tratamento com soroterapia e como uma fonte rica de potenciais inibidores de toxinas envolvidas em várias fisiopatologias humanas e doenças animais (DE LUCENA; MENDES; BRANDEBURGO, 2008).

\section{Agente anticancerígeno}

Pesquisa feita por Costa et al. (2010) indicou que o polímero rico em proantocianidina (F2) do Stryphnodendron adstringens que foi obtido a partir da casca do caule não possui atividade genotóxica, concluindo que a utilização do F2 parece ser seguro, e com potencial farmacológico.

Seguindo essa mesma linha, Santos-Filho, Ferreira e Gouvêa (2011) ao determinar a atividade antigenotóxica de extratos de folhas de Stryphnodendron adstringens e o potencial antioxidante dos extratos in vitro onde os extratos apresentaram teor alto de compostos fenólicos, flavonoides e proantocianidinas e todos os extratos apresentaram ação antioxidante, confirmando os ótimos efeitos do barbatimão como agente anticancerígeno.

Ação protetora contra química induzida genotoxicidade e da atividade do radical livre do extrato das folhas do barbatimão foi determinada a atividade antigenotóxica deste extrato. induzida pela $\mathrm{PB}$ em células de rato de medula óssea e potencial antioxidante dos extractosin vitro.

Santos Filho, Ferreira e Gouvêa (2011) demonstraram que os extratos apresentam atividade antioxidante protegendo células de genotoxicidade induzida por ciclofosfamida em células da medula ósseas de ratos extractosin vitro. Assim, os resultados confirmam os efeitos benéficos do barbatimão.

A atividade anticarcinogênica é evidenciada por comunidades que consomem o chá verde, rico em ácido tânico e outros polifenois, em grandes quantidades mostra-se baixo o risco de desenvolver câncer gástrico. Estudos recentes mostram que vários taninos atuam como captadores de radicais, os quais interceptam o oxigênio ativo formando os radicais estáveis, prevenindo o câncer (MELLO et al., 2001 apud MONTEIRO; DE ALBUQUERQUE; ARAÚJO, 2005). 


\section{CONCLUSÃO}

Devido à miscigenação das culturas Africana, indígena, europeia surgiram comunidades que há muito tempo utilizam as plantas para curar seus males passando o conhecimento para gerações seguintes. Utilizam essas plantas medicinais de várias maneiras, com diferentes partes das plantas e para muitas doenças.

Esses fitoterápicos são definidos como derivados de droga vegetal e são assim caracterizados por conter qualidade, efeitos terapêuticos comprovados, padraõ de composição e a segurança do uso pela população, diferente das plantas medicinais ou suas partes, que não são consideradas medicamentos, são usadas pela população como método alternativo para o tratamento de doenças, mas suas propriedades medicinais não são comprovadas.

O extrato de Stryphnodendron adstringens apresenta moléculas com propriedades, antiofídicas, que neutralizam a peçonha de serpentes. Pode ser usado para o tratamento com a soroterapia, que possui potencial inibidor de toxinas (DE LUCENA; MENDES; BRANDEBURGO, 2008, DE PAULA, 2009).

A planta Stryphnodendron adstringens conhecida como "Barbatimão", que foi o objeto de estudo desta revisão bibliográfica, foi bastante estudada. Essa pesquisa mostra que o Barbatimão utilizado por várias pessoas nas regiões, é uma importante planta medicinal, com propriedades medicinais comprovadas, possuindo em sua casca em suas folhas, substâncias ativas como taninos condensados que são ricos em polímeros proantocianidinas que inclui vários flavanoides como prodelphinidins e prorobinetinidins, e ainda outros constituintes químicos, como alcaloides, flavonoidesdes, terpenos, estilbenos, esteroides, inibidores de proteases (como a tripsina).

As folhas e cascas são usadas nas formas de chás, em pó, extratos alcoólicos, contra vários tipos de infecções, sejam essas causadas por inúmeros tipos de bactérias, fungos e ainda sendo importante agente antiofídico alternativo, no tratamento junto com a soroterapia, contra os principais efeitos biológicos do veneno de Lachesis muta (Surucucu), Bothrops moojenim e Bothrops pauloensis (Jararaca).

O extrato da casca de $S$. adstringens possue grande potencial antimicrobiano, destacando-se como preocupação com a descoberta de novos medicamentos, e também com a conscientização do uso sustentável dessas plantas medicinais.

A utilização de produtos naturais, derivados de plantas, como alternativa terapêutica para o tratamento de várias doenças é importante assunto para discutir e pesquisar, já que muitas comunidades usam plantas medicinais, às vezes, somente as plantas.

Conclui-se que o uso feito na medicina popular é apropriado em relação à estudos feitos, mostrando, que o barbatimão age como antimicrobiano, antiparasitário, contra ação de enzimas de veneno de serpentes e ainda há estudos mostrando que não é genotóxico, indicando uma segurança em sua utilização.Mas mesmo com essas comprovações é preciso analisar mais sobre como essas plantassão comercializadas, como são usadas pela população, pois além de ajudar as pessoas autilizarem de forma correta, contribui para a descoberta de novos agentes fitoterápicos contra várias doenças, causadas por inúmeros fatores.

Por mais que essas propriedades medicinais do Stryphnodendron adstringens estejam comprovadas é preciso mais pesquisas para ressaltar sua importância como agente antimicrobiano e para outras afecções. É preciso mais pesquisas com o Barbatimão e também com muitas outras plantas utilizadas de forma empírica, que podem facilitar os pesquisadores a desenvolverem novos

Persp. online: biol. \& saúde, Campos dos Goytacazes, 11 (3), 14-32, 2013

seer.perspectivasonline.com.br 
agentes contra inúmeros tipos de doenças.

\section{REFERÊNCIAS BIBLIOGRÁFICAS}

Agência Nacional De Vigilância Sanitária - ANVISA. Disponível em: http://www.anvisa.gov.br/medicamentos/fitoterapicos/definicao.htm, 2003. Acesso em 24 jun. 2012

Associação Brasileira Das Empresas Do Setor De Fitoterápicos, Suplemento Alimentar E De

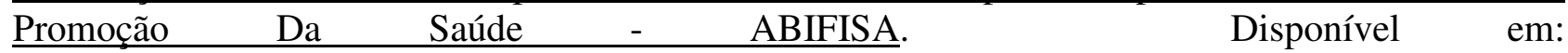
http://www.abifisa.org.br/saibamais_historico.asp, 2012. Acesso em 19 mar. 2012.

ALMEIDA, S.P. et al. Cerrado espécies vegetais úteis. $1^{\circ}$ Edição. Planaltina, DF. EMBRAPACPAC, 1998, p. 106-110, 129-133, 182-185, 223-225 e 347-350.

BARBOSA, C.K.R. et al. Qualidade microbiológica de plantas medicinais cultivadas e comercializadas em Montes Claros, MG. Instituto de Ciências Agrárias, Universidade Federal de Minas Gerais. Revista Biotemas, v. 23, n. 1, mar. 2010.

COSTA M.A. et al. Safety evaluation of proantho cyanidin polymer-rich fraction obtained from stem bark of Stryphnodendron adstringens (BARBATIMÃO) for use as a pharmacological agent. Regulatory Toxicology and Pharmacology. Editora Elsevier, p. 330-335, 2010.

CHUNG, K.; WEI, C.; JOHNSON, M.G. Are tannins a double-edged sword in biology and healt. Trends in Food Science and Technology, Amsterdam, v.9, n.4, p.169-174, 1998.

CHUNG, K. et al. Crit. Rev. Food Sci. Nutrition 1998, 38, 421.

DE LUCENA M.N.; MENDES M.M.; BRANDEBURGO M.I.H. Neutralização dos principais efeitos enzimáticos e biológicos de peçonhas botrópicas brasileiras pelo extrato aquoso de Stryphnodendron adstringens. XII Seminário de Iniciação científica.Universidade Federal de Uberlândia, 2008.

DE PAULA R.C. Efeito de extratos vegetais sobre atividades biológicas do veneno da serpente Lachesis muta. Dissertação Mestrado em Neuroimunologia. Universidade Federal Fluminense, Instituto de biologia programa de neuroimunologia. Tese de mestrado, 2009.

EMBRAPA. EMBRAPA CERRADO:VI Plano Diretor da EMBRAPA Cerrados. Disponível em: http://www.cpac.embrapa.br/publico/pdu2008-2011.pdf. 2008. Acesso em: 11 dezembro 2011.

ETHUR, L.Z. et al. Comércio formal e perfil de consumidores de plantas medicinais e fitoterápicos no município de Itaqui - RS. Rev. Bras. Pl. Med., Botucatu, v. 13, n. 2, p. 121-128, 2011.

FIRMO, W.C.A. et al. Contexto histórico, uso popular e concepção científica sobre plantas medicinais, Cad. Pesq., São Luís, v. 18, n. especial, dez. 2011.

GONÇALVES A. L. Estudo da atividade antimicrobiana de algumas árvores medicinais nativas com potencial de conservação/recuperação de florestas tropicais. Tese apresentada ao Instituto de Biociências do Campus de Rio Claro, Universidade Estadual Paulista como parte dos requisitos para a obtenção do título de Doutor em Ciências Biológicas (Área de Concentração: Microbiologia Aplicada). Rio Claro Estado de São Paulo - Brasil, p. 13, Dez. 2007.

GLASENAPP, J. S. Variação aloenzimática e estrutura genética populacional de Stryphnodendron adstringens (Mart.) Coville (Leguminosae). Tese pós-graduação em genética e melhoramento.Universidade Federal de Viçosa, fevereiro de 2011. Orientador: Vicente Wagner Dias Casali. Coorientadores: Cosme Damião Crus e Ernane Ronie Martins.

HERZOG-SOARES, J.D. et al. Atividade tripanocida in vivo de Stryphnodendron adstringens (barbatimão verdadeiro) e Caryocar brasiliensis (pequi) Rev. Bras. Farmacogn., v. 12, supl., p. 0102, 2002.

Persp. online: biol. \& saúde, Campos dos Goytacazes, 11 (3), 14-32, 2013 
ISHIDA, K. et al. Influence of tannins from Stryphnodendron adstringens on growth and virulence factors os Candida albicans. Journal of Antimicrobial Chemotherapy, p. 8, 2006.

ISHIDA K. et al. Activity of tannins from Stryphnodendron adstringens on Cryptococcus neoformans: effects on growth, capsule size and Pigmentation. Annals of Clinical Microbiology andAntimicrobials, v.8, n.29, 2009.

LOPES G.C. et al. Determinação quantitativa de taninos em três espécies de Stryphnodendron por cromatografia líquida de alta eficiência. Brazilian Journal of Pharmaceutical Sciences, v. 45, n. 1, jan./mar., 2009.

LUIZE P.S. et al. Effects of medicinal plant extracts on growth of Leishmania (L.) amazonensis and Trypanosoma cruzi Revista Brasileira de Ciências Farmacêuticas Brazilian Journal of Pharmaceutical Sciences vol. 41, n. 1, jan./mar., 2005.

MELO E. et al. Evaluation of the antifungal potential of brazilian cerrado medicinal plants. Mycoses, p.511-517, 2009.

MELLO, J.P.C. et al. orgs. Em Farmacognosia: da planta ao medicamento. UFSC: Porto Alegre; 3. ed., 2001.

MELO, J.A. Valorização da flora do cerrado com importância medicinal. Universidade de Brasília. Trabalho de Conclusão de Curso, Luziânia: p.11-19, 11 dez. 2011.

MELO, J.G. et al. Qualidade de produtos a base de plantas medicinais comercializados no Brasil: castanha-da-índia (Aesculus hippocastanum (L.), capim-limão (Cymbopogoncitratus (DC.) Stapf) e centela (Centella asiatica (L.) Urban). Acta Botanica Brasilica, v. 21, n. 1, p. 27-36, 2007.

MONTEIRO J.M.; DE ALBUQUERQUE, U.P.; ARAÚJO, E.L. Taninos: uma abordagem da química à ecologia. Quim. Nova, p. 892-896, v. 28, n. 5, 2005.

PINHO, L. et al. Atividade antimicrobiana de extratos hidroalcoolicos das folhas de alecrimpimenta, aroeira, barbatimão, erva baleeira e do farelo da casca de pequi. Ciência Rural, Santa Maria, v.42, n.2, p.326-331, fev, 2012.

RODRIGUES, V.E.G.; CARVALHO D.A. Levantamento etnobotânico de plantas medicinais no domínio do cerrado na região do Alto do Rio Grande-Minas Gerais. Ciênc. agrotec., Lavras, v. 25, n. 1, p. 102-123, jan./fev., 2001.

SANO, S.M.; ALMEIDA, S.P.; RIBEIRO, J.F., Cerrado- Ecologia e Flora, capítulo-6, As principais Fitofisionomias do bioma do cerrado. 1.ed. Brasília: EMBRAPA, p. 153-197, 2008.

SANTOS FILHO P.R.; FERREIRA L.A.; GOUVÊA C.M.C.P. Protective action against chemicalinduced genotoxicity and free radical scavenging activities of Stryphnodendron adstringens ("barbatimão") leaf extracts. Revista Brasileira de Farmacognosia Brazilian Journal of Pharmacognosy, v. 21 n.6: p. 1000-1005, Nov./Dec. 2011.

SANTOS, P. G.; SIANI, A. C. Consolidação dos Grupos de Pesquisa em Plantas Medicinais e Fitoterápicos no Brasil. Revista Virtual Química, v. 5, n.3 p. 438-449, data de publicação na Web: 8 de junho de 2013.

SANTOS, S.J.D.; ALVES, F. Análise comparativa da ação de extratos de plantas com atividade antimicrobiana (in vitro) sobre cepas de Staphylococcus aureus RBAC, v.02, n.04, Belo Horizonte, MG, Dez de 2012.

SCALBERT, A. Antimicrobial properties of tannins. Phytochemistry, Elsevier v.30, p.3878-3883, 1991. 
SILVÉRIO, J.P. Manual de fitoterapia e plantas medicinais úteis (Especialmente as do Cerrado. $1^{\circ}$ Edição. Brasília, DF. RBS Gráfica e Editora. 2008, p. 257, 271, 319.

SINGH, B.; BHAT, T.K.; SHARMA, O.P. Biodegradation of tannic in an ruminal system.Livestock Production Science, v.68, p.260-261, 2001.

SOARES, S.P.; VINHOLISA, L.A.C.; SILVA, M.L.A. Atividade antibacteriana do extrato hidroalcoólico bruto de Stryphnodendron adstringens sobre microorganismos da cárie dental. Rev. odonto ciênc.v. 23, n. 2, p. 141-144, 2008.

THOMAZI, G.O.C.; BERTOLIN, A.O.; PINTO, M.D.S. Atividade Antibacteriana in vitro Do Barbatimão e da Mangabeira Contra bactérias relacionadas às Infecções do trato urinário Anais do I Seminário Internacional de Ciências do Ambiente e Sustentabilidade na Amazônia, 2010.

VASCONCELOS, M.C.A. et al. Avaliação de atividade biológicas das sementes de Stryphnodendron obovatum Benth (Leguminosae). Rev Bras Farmacogn, p. 121-127, 2004.

VEIGA JUNIOR, V. F. Estudo do consumo de plantas medicinais na Região Centro-Norte do Estado do Rio de Janeiro: aceitação pelos profissionais de saúde e modo de uso pela população. Revista Brasileira de Farmacognosia, v. 18, n. 2, p. 308-313, 2008. 